\title{
Assessing preschool education quality via the ECERS-R scales
}

\author{
Irina Kulikovskaya*, Raisa Chumicheva, Lyudmila Kudinov, and Maria Guryeva
}

Southern Federal University, 344006, Rostov-on-Don, Russia

\begin{abstract}
The article covers current trends in the worldwide experience of quality assessment in preschool education. The authors have analyzed the world's best practices in assessing the quality of preschool education. One of the tools recognized in the world community is the ECERS-R scale. The authors share understanding of the ways to apply these scales to quality assessment in accord with the requirements of the Federal State Educational Standard for preschool education and make it possible to assess the quality of conditions for development, moral instruction and education of preschool children. The ECERS-R scores make it possible to reveal the development vector of a preschool educational organization. When using ECERS-R scales for a comprehensive assessment of the quality of education in preschool educational organizations, the assessment becomes the key to the development of the preschool establishment. Identifying and bridging the gap between the norm of the standard and activities of the institution, i.e. the goal and the reality, shape the key directions in work. On the basis of this assessment, a program for development of a preschool organization should be defined. The authors conducted a research on introducing the ECERS-R scales into activities of the teaching staff to improve the quality of interaction between employees. The researchers worked out and implemented a plan for improving staff interaction and collaboration based on the ECERS-R scales. The work carried out showed a significant qualitative improvement in the interaction between employees, which consequently affects the education quality.
\end{abstract}

\section{The Issue of Preschool Education Quality Assessment}

Close attention to the quality of preschool education is caused by the changes that have occurred in the modes of children education over the past year. Active introduction of distance education tools, caused by the coronavirus pandemic, has led to a heated discussion in society about the impact of digitalization on the development of children, their health, success in social communication and knowledge of the world around.

Quality as a concept is interpreted ambiguously: essential signs, properties, features that distinguish one object or phenomenon from another; property, dignity, degree of suitability for something. According to the international quality standard ISO 9000: 2015 "“"Quality management systems - Fundamentals and vocabulary", quality refers to the way inherent characteristics fulfill the requirements". The concepts and principles of quality management

* Corresponding author: iekulikovskaya@sfedu.ru 
described in this Standard give organizations an opportunity to meet contemporary challenges that are strikingly different from those of recent decades.

The activities of a preschool educational organization in the modern sociocultural space are undergoing significant changes. The influence of quality goes beyond customer satisfaction: it can also have a direct effect on an organization's reputation. A quality-centered organization encourages the culture that is reflected in behavior, attitudes, actions and processes that create value by meeting the needs and expectations of customers and other parties concerned. The quality of the organization's products and services is determined by the ability to meet the needs of parents (legal representatives).

Traditionally, the quality of education is understood as meeting the standard requirements. The Federal State Educational Standard for preschool education out-lines important provisions related to supporting the diversity of childhood; preserving the uniqueness and intrinsic value of childhood as an important stage in the general development of a person, considering childhood as a period of life that is significant in itself, without any conditions; personal developmental and humanistic nature of interaction between adults (parents (legal representatives), pedagogical and other employees of the organization) and children. These provisions indicate the requirements to preschool education quality. When implemented, any standard implies certain risks, and the preschool education standard is no exception. It de-fines those values that were not directly expressed in preschool education programs earlier. Thus, it raises the issues of initiative, fostering responsibility, possession of cultural values, ability of a child to make choices, etc.

\section{Quality of Preschool Education Worldwide}

\subsection{Quality of preschool education as reflected in research}

G.A. Omanova investigated the quality of educational process in preschool or-ganizations by means of monitoring. As a result, education quality was defined and education goals and ways to achieve them were formulated. The author is convinced that there is an urgent need to create a structure that regularly evaluates the quality of education and identifies "growth points", i.e. problems and shortcomings that need to be primarily addressed [1].

E. Andrew, O. Attanasio, R. Bernard, L. Cardona-Sosa, S. Krutikova and M. RubioCodina argue that children's access to pre-school education is improving all over the world, but its quality leaves much to be desired. The authors conducted a randomized trial to evaluate two approaches to improving the quality of Colombian preschools. The first approach implied finding additional resources for purchasing materials and training personnel. This approach has not brought any tangible results. The second approach additionally implied training teachers to employ innovative technologies. This approach made it possible to improve the quality of education and develop children cognitive abilities [2].

A. M. Caridad, A. Martin, and others studies the quality of preschool education from the point of view of children's well-being. This is an important characteristic, since children who are well-off in the first years of life are quite likely to become healthy and successful citizens in the future. Children development is influenced by the experience they gain, accumulated in the family and kindergarten. This is why parents, other relatives, educators, and the government must improve these experi-ences to improve the well-being of children. [3]

S. Wortham explores the global perspectives of early childhood education. The global problem, she believes, is how preschool education is conducted in many dif-ferent cultures and settings. Economic, geographical, and cultural factors influence the content of programs for children around the world [4]. 
H.Yoshikawa, A. Vermli, and others have worked out a research program based on the system-level factors - at the national, subnational, local, or municipal levels. These levels may facilitate or limit the implementation of the program. The authors have shown that, thanks to decades of evidence in support of early childhood de-velopment programs and policies, investment is increasing worldwide $[5,6]$.

Quality as a priority of preschool education is considered in the UNICEF docu-ments. The value of preschool education for subsequent success in school and later on life is noted. In kindergarten, children receive important soft skills that will al-low them to maintain their curiosity and contribute to a peaceful society and thriving economy. The quality of preschool education is considered as the combination of many components, including teachers, family, resources, and curricula [7].

\subsection{Factors and conditions of high-quality preschool education}

The Russian professional standard "Teacher (pedagogical activity in preschool, primary general, basic general and secondary general education)" reveals the labor actions of a teacher. They are associated with participation in the planning and ad-justment of educational tasks (together with a psychologist and other specialists), as well as compliance with legal, moral and ethical standards, the requirements of pro-fessional ethics [8, p.13, 14]. The new requirements actually expand the competence of the teacher to the level of a universal specialist who has the skills of an ed-ucator, psychologist, defectologist, child physician, who knows how to work with special children, how to find an approach to each student, how to convey the re-quired information, how to reveal hidden potential and be able to interact with other professionals.

Management culture is an important condition and outcome in achieving the high quality of education. It is important for a leader to know and satisfy the profession-al needs of employees, to stimulate individual and collective activities, ensuring the growth of their skills [9].

In this respect, necessary management activities include: communicating with the staff to make sure they understand the importance of their personal contributions; promoting collaboration within the organization; promoting open discussion and exchange of knowledge and experience; empowering employees to identify work bottlenecks and offer initiatives without fear; recognition and appreciation of the contributions, knowledge and skills; providing the opportunity for self-assessment of the performance of employees to meet their personal goals; conducting employee satisfaction surveys, communicating their results and implementing appropriate actions to improve corporate interaction.

Realizing education in the context of culture, we can give the management sys-tem a different direction. It will ensure the emergence of new qualitative character-istics, both in the development of a child and a specialist. Relationships and interac-tion between teachers are included in the group of socio-pedagogical conditions for the functioning and development of a pedagogical system focused on achieving high quality of education. Organizational and managerial activity has the following cultural characteristics: material and spiritual values, effectiveness of their use, functioning, value-oriented principles of setting goals, the content of education and the spatial-objective environment, cultural samples and standards. 


\section{Interaction within the Preschool Organization Aimed at High Education Quality}

Lack of well specified technical and technological measures (who, when, what and how to measure) leads to certain problems in assessment practice. The un-doubted relevance and importance of assessing the quality of preschool education prompted us to turn to an innovative tool - the ECERS-R scales [10]. Estimates on the ECERS-R scales make it possible to determine the vector of development of a preschool educational organization. However, use of the ECERS-R scales requires certain expertise of teachers.

Early D. M., Sideris J. et al. investigated the Environment Assessment Scale for Young Children-Third Edition (ECERS-3). They studied the reliability of the esti-mates made. This served as the basis for their widespread use in mass practice in many countries of the world. The USERS3 scale study was conducted in 1,063 preschool classrooms in three states. As a result, it was shown that one factor can-not adequately reflect the variability of the elements. Overall ECTS-3 scores, learn-ing opportunities, and teacher interaction were positively associated with the growth of control functions, as were all three areas of CLASS Pre-K. The results showed the value of a tool for assessing the quality of preschool education [11].

E.G. Yudina claims that the ECERS-R scale is a very interesting tool for studying the quality of preschool programs, especially in connection with international com-parative studies, since they are the undisputed leader in the number of countries where they are used. These scales have been successfully tested in Russian pre-school educational institutions. It was concluded that their content meets the basic requirements of the Federal State Educational Standard for preschool education [12]. This is explained by the general philosophy of the documents: understanding the child as an active participant in educational relations; equal rights of all academic process participants; adequacy of conditions (material, spatial, temporal) for the development of children's activity and meeting children's interests.

In any preschool educational organization, interaction is inherently social, since it involves participants being representatives of society $[13,14]$. In the context of the problem of assessing the quality of preschool education, it is difficult to overesti-mate the importance of employing one of the most authoritative international mod-ern assessment tools, tested in many countries and well-proven in practice - the ECERS-R scales for a comprehensive assessment of the quality of education in a preschool educational organization.

The core idea of the ECERS-R scales is focused on Vygotsky's judgments about social constructivism. The construction of child's knowledge occurs through the interaction with peers and adults. Therefore, it is necessary to reconsider the atti-tude towards the child, and the idea that the child is a competent, knowledgeable, personality with his/her own world view [15].

The paradigm of "participation" in modern high quality preschool education:

- is based on the child's world view;

- stimulates the expression of one's attitude to a situation;

- encourages the discovery of knowledge in communication with peers and adults;

- develops reflection [16].

One more important question arises: "Is a tool worked out for one country suita-ble for others?" The ECERS-R tool has been used many times in the international community which shows the universality of the quality of education. Despite obvi-ous cultural differences and national traditions, during preschool childhood a child should gain experience of activity, proactive actions, decision-making, expression of themselves through a symbol/sign. These principles have become generally ac-cepted in various educational systems. We know quite a few countries that use ECERS-R scale, such as the USA, the UK, Italy, Sweden, Germany, Portugal, Spain, Iceland, Norway, Singapore, Korea, Romania, Greece, Cyprus, South Korea, etc. All countries have a different approach to education, and they all find it acceptable 
to use the ECERS-R tool to assess the quality of education. Different countries have different ways of using the ECERS-R scales. Basically, the use is associated with the stimulation of preschool educational organizations. Based on the results of the assessment, institutions receive additional funding or a number of teachers undergo advanced training, or the scale is included in the national educa-tion system.

According to the EPPE study (British Longitude 1997-2014) a high quality pre-school education retains a beneficial effect on a child until the end of school stud-ies. The ECERS scale was used to control all variables and the researchers report interesting findings in this respect. Based on the quality of preschool education and time spent in preschool, it was easy to predict the results of graduation exams. In other words, those children who attended preschool institutions with high quali-ty academic processes, and those who spent longer time in preschool, planned to take more final exams and received higher score in the English language and Math-ematics exams. It can be interpreted that the impulse that the child received in pre-school childhood is significant for the entire school period, and the ECERS$\mathrm{R}$ scale can be used as an assessment tool for evaluating this impulse.

\section{Improving Interaction Quality of the Kindergarten Teaching Staff by Using the ECERS-R Scales}

The practical part of the research was to introduce the ECERS-R scale into the system of improving the quality of interaction in the teaching staff.

The main tasks at this stage were:

1. Develop a plan to improve the interaction and cooperation of preschool staff according to the ECERS-R scales.

2. Implement a program to improve the quality of interaction between preschool staff, focusing on the indicators in the ECERS-R scales.

Based on the obtained data and conclusions, we worked out a plan to improve the interaction and cooperation within the staff according to the ECERS-R scales. Previously, we received low indicators for the following criteria: "Results of the performance assessment are provided to all employees in writing at least once a year", "Employee interactions are positive and create a sense of warmth and sup-port", "The responsibilities of each employee are clearly defined". The research re-vealed inefficient use of the methodical office and insufficient information ex-change between employees necessary to meet the needs of students.

To solve these problems, we have implemented a program to improve the quality of interaction between the staff of the preschool organization, the results of which can be stated as follows. For the implementation of the pedagogical project "Me-thodical office - the area for teachers", the premises of the methodical office were transformed: several workplaces were organized, a laptop, a color printer, a lamina-tor, chairs, a tea set, an electric kettle were purchased. A creative group of special-ists and educators created card files of visual materials, available literature, disks, presentations, a list of articles from books and magazines for the implementation of annual tasks. As for other important events, the organization arranged topic-related exhibitions of methodological literature, interaction with the library of V. Shukshin to provide literature in accordance with the reader's interests of employees. Teach-ing materials, such as photos, videos, presentations were systematized in the corporate laptop and the rules for accumulation of pedagogical materials have been de-fined.

At the workshop "Evaluating the effectiveness of personal and professional growth of a teacher", which was held in January 2017, the staff was made familiar to the ECERS-R scales, namely, indicators that describe staff interaction. As a result of the seminar, the employees responded positively to the new system for evaluat-ing the quality of interaction. The connection between the interaction of the staff and the quality work of the teacher was 
also explained. Teachers took part in some training sessions devoted to effective ways of conflict resolutions.

The master-class "Interaction of employees in the name of children's develop-ment", conducted by a teacher-psychologist, contributed to the development of teachers' readiness to implement various types and forms of interaction that affect the quality of children's education. A series of greetings and goodbyes in various cultural practices, acceptable expressions of their feelings, approval and recognition of merits in academic performance, expressions of support, faith in their own strengths and capabilities and some other techniques received positive emotional response from the teachers. After the event, the teachers discussed the topic: "What kind of interaction is most acceptable in the modern world", "How do the forms of interaction affect the mental state of the opponent, his future"? As a result, most teachers came to the conclusion that personal-oriented interaction is the most productive form.

The round table "My Partner and Me" appeared to be most popular among the participants-educators, junior educators and specialists of the institution. Although the goal was to enhance teachers' desire to independently distribute responsibilities between educators of the same age group and related to the interaction of two edu-cators in the group, the topic seemed attractive to many staff members. They dis-cussed the issues of perception of each other, both visible and invisible sides of contacts, internal relations and relations of demonstration, the problems of power, control, quick temper and the development of empathy, how to make a relationship mutually beneficial and expand the space of a partner (to help fulfill official duties, please, give compliments, support if necessary, etc.).)

Project activities to develop the ability of teachers to do effective reports on self-analysis of their professional activities started according to the annual plan at the end of the school year and coincided with the beginning of teacher observations. After each demonstration of pedagogical experience, the teacher voiced the intro-spection of the event (educational activity, the result of the project, story-role-playing game, entertainment), and then the discussion was continued by the teach-ers present. The experience gained, of course, had a positive impact on the quality of self-reports presented at the final pedagogical council.

In March, a round table was held where teachers shared their views on changes in the working process. They discussed transformations in interaction with all par-ticipants of the educational process, in the organization of working hours and in the design of the pre-school environment. It should be noted that some participants of the round table identified some inner barriers in overcoming regular daily problems emerging in their work. However, after a minor change in the workflow according to the ECERS-R scales, they found out that organization of working hours as well as interaction with other staff became easier.

A series of summer training sessions was aimed at practical development of the knowledge gained as a result of working at practical seminars. The following topics were covered at training sessions: Developing mutual respect in a dialogue, ability to attract and retain attention in group activities, ability to say "no", and others.

To build team spirit, the employees took part in the "Spartakiad" where the team of employees of the Kindergarten No. 95 of JSC Russian Railways competed with the teams of other educational institutions of JSC Russian Railways. During the training, the employees felt like a team capable of solving tasks that are not related to professional activities. Joint creativity in inventing the name of the team and its motto, doing sports tasks brought the employees closer together and prompted the desire to organize weekly classes in the sports club "Grace". To improve the work in the team, a team building event called "The union is our only strength" was held during which teachers were faced with tasks that they could only cope with as a group. During team-building, the teachers joined forces and successfully coped with all the tasks, enjoying the process immensely. As a result, it was possible to see that the 
participants were able to find a model of successful interaction, without making personal claims, which is one of the main factors of successful work.

At the end of our work, a round table "Innovations in professional activity: achievements and prospects" was held. The teachers talked about their successes, which seemed especially hard to do, shared their experience in making changes in the working process. The teachers who receive education in the SFU Master's pro-gram presented their experience of mastering new technologies. Employees who completed distance training courses presented reports on the topics of the course preparation. The round table ended with a tea party of medicinal herbs collected on the ecological trail of the institution. After the round table, the wishes of the staff were taken into account and residual problems in the interaction of the staff were identified in order to develop a plan for the next year to maintain productive staff interaction.

\section{Results}

The developed and implemented plan for improving the interaction and coopera-tion of staff according to the ECERS-R scales enable us to achieve a qualitative im-provement in the interaction of employees, which consequently affects the quality of children education.

The control stage of the experimental work made it possible to find a positive trend in the results of the work carried out. Measures for organizing the subject-spatial environment of a preschool educational institution (the schedule of work of specialists' offices, a music and sports hall), the development of general rules for the interaction of employees, thematic exhibitions in the teaching room at the request of educators and the project activities of micro groups in the teaching room have increased the importance of the teaching room.

Comparative data of the ascertaining and control stages of the experiment are presented in Figure 1.

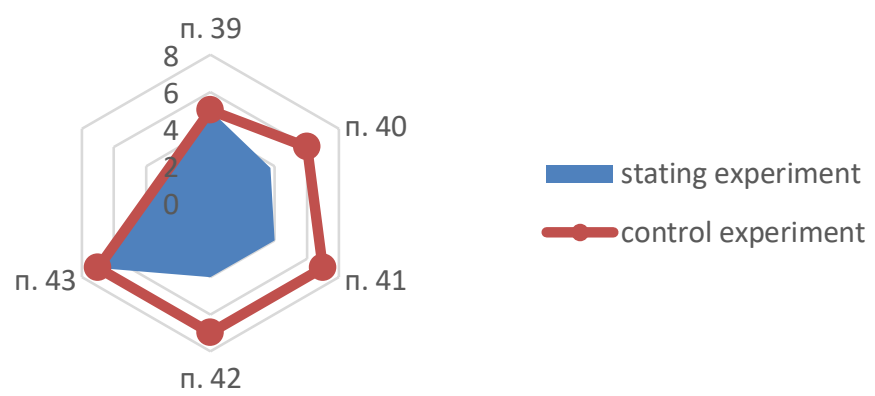

Fig. 1. Comparative data of the ascertaining and control stages of the experiment.

Thus, the ECERS-R scale specifies requirements of the standard and is its opera-tional continuation. The ECERS-R scales cannot be used for monitoring and rating purposes because in this case the idea of using scale for developmental aims is lost and this might lead to overestimation of the results obtained.

\section{References}

1. G.A. Omanova, International scientific review. LXXII. https://cyberleninka.ru/article/n/monitoring-educational-quality-in-preschooleducational-organization (2020). 
2. A. Andrew, O. Attanasio, R. Bernal, L. Cardona-Sosa, S. Krutikova M. Rubio-Codina, National Bureau of Economic Research 26191. http://www.nber.org/papers/w26191.pdf (2019)

3. M. Caridad Araujo, N. Schady, The early years: Child well-being and the role of public policy 1 (4), 91-120 (2015). Inter-American Development Bank, Washington.

4. S. Wortham, Global Perspectives in Early Childhood Education. Springer, San Antonio (2013)

5. H. Yoshikawa, A.J. Wuermli, A. Raikes, S. Kim, S.B. Kabay, Directions for research in global contexts. Social Policy Report 31 (1), 1-36 (2018)

6. H. Yoshikawa, C. Weiland, J. Brooks-Gunn, M. Burchinal, L. Espinosa, W. Gormley, M. Zaslow, Society for Research in Child Development, New York (2013)

7. Unicef $A$ world ready to learn: Prioritizing quality early childhood education. UNICEF, New York (2019)

8. Professional standard. Educator (Perspektiva, Moscow, 2014)

9. R.M. Chumicheva, Quality management of preschool education (Rostov-on-Don, 2001)

10. T. Harms, R.M. Clifford, D. Cryer, Early Childhood Environment Rating scale (ECERS3) (Teachers College Press, New York, 2014).

11. D.M. Early, J. Sideris, J. Neitzel, D.R. La Forett, C.G. Nehler, Third Edition (ECERS3) Early Childhood Research Quarterly 44, 242-256 (2018).

12. E.G. Yudina, Modern preschool education. Theory and practice 7, 22-27 (2015).

13. V.S. Ageev, Intergroup interaction (Moscow, Rech., 1990)

14. I. Kulikovskaya, R. Chumicheva, L. Kudinova, Parent choice: child or career?, SHS Web of Conferences 72 (2019). International Scientific Conference: “Achievements and Perspectives of Philosophical Studies" (APPSCONF-2019). Rostov-on-Don, Russia, November 25-27, 2019. DOI: https://doi.org/10.1051/shsconf/20197204013 (2019)

15. I.E. Kulikovskaya, Middle East Journal of Scientific Research 15 (5), 698-706 (2013).

16. K. Pascal, T. Bertram, Modern preschool education. Theory and practice 1 (2015). 